\title{
Strategy for Risk Avoidance of Chinese Educational Institution Going Global
}

\author{
Yijun Li \\ Henan Provincial Foreign Science\&Technology Exchange Centre \\ Zhengzhou, China, 450003
}

\begin{abstract}
With the deepening of reform and opening up, more and more domestic enterprises going global. In order to avoid various risks and to ensure sustainable development of Chinese Educational Institutions going global, this study gives several suggestions for them to follow.
\end{abstract}

Keywords-Risk Avoidance; Chinese Educational Institution; Going Global

\section{INTRODUCTION}

With the deepening of reform and opening up, more and more domestic enterprises going global. According to the statistics released by Ministry of Commerce, by the end of 2012, Chinese Educational Institutions have invested in 3391 non-financial foreign enterprises in 132 foreign countries and regions. ${ }^{1}$ And the accumulated foreign direct investment is up to $\$ 280$ billion. The enterprises "going global" have unlimited business opportunities. Meanwhile, they also encounter many risks that may not only lead to heavy financial loss; it may also damage the image of the enterprise. More severely, the relevant persons may go to jail and it has negative influence on plans for global expansion. The lack of awareness about the problem and insufficient support of information about the risks existed posed major challenge for enterprise to maintain healthy and sustainable development. Therefore, it is a key issue for Chinese Educational Institutions going global to consider in avoiding risks and maintaining development.

The structure of this assay is organized as follows: the first part gives a brief introduction of the study and illustrates the significance the study. The second part is the main part of the study and it makes an detailed analysis of the problems and challenges faced by the Chinese Educational Institutions going global, following that, suggestions and advices are raised for the Chinese Educational Institutions going global to follow in accordance with the problems and challenges faced by the Chinese Educational Institutions going global analyzed above. Conclusions and inspirations are made in the third part. Acknowledgement is given in the fourth part which is the final part of the study.

\footnotetext{
1 Yang Xue . Analysis for Chinese Educational Institution Going Global, Research of Education.2011 (9)
}

\section{ANALYSIS}

A. Problems and challenges faced by the Chinese Educational Institutions going global

There are some problems and challenges faced by the Chinese Educational Institutions going global.

1) Chinese Educational Institutions attached more importance on the product, project, program they provided for the foreign market. They do not attached great importance on the tradition and culture of the foreign country. Instead of doing things according to the local culture and tradition and be in line with foreign practices, they still do things in a domestic way. For instance, one of the Chinese Educational Institutions blindly attached great importance to its close relationship with different government organizations in different levels in China, which actually repelled the foreign party.

2) Chinese Educational Institutions do not fully exploit various resources to reduce the inconvenience caused by the difference existed in cultural and institutional difference between China and foreign countries to the some extent. In terms of the evaluation and approval of the new project, Chinese Educational Institutions do not communicate much with local organizations such as accounting agencies, tax agencies and law firms and people who is in charge of approval procedures. At the same time, they do not get enough information from intermediaries such as accounting agencies, tax agencies and law firms but also contact closely with the officials who are in charge of the examination and the approval of the project to let them have more information about the enterprise to avoid the traps in administrative procedures.

3) Chinese Educational Institutions going global have not done a lot of work in keeping good relationship with local enterprises and individuals. They do not cooperate closely with the local enterprise and employee local talent as much as possible. Moreover, Chinese Educational Institutions do not keep close relationship with the political representatives to let them know that the contribution of the Chinese Educational Institutions to the increase of the employment and the development of local economies. In addition, Chinese Educational Institutions 
do not contact closely with the media that is very powerful, either.

4) Chinese Educational Institutions going global do not attach importance to the enterprise publicity strategy. Chinese Educational Institutions still have long way to go for local residence to have sufficient information about the virtues of the Institutions, including advanced technology and the development prospect of the Chinese Educational Institutions and so on. The management of the Chinese Educational Institutions should make people concerned understand and know about the contribution of the Chinese Educational Institutions and its great value to the society. In terms of carrying out social liability, Chinese Educational Institutions should let the people local know the great contribution of the Institution to local economy growth and the development of the community and the society. This has been the best opportunity to promote the image of the Chinese Educational Institutions going global. $^{2}$

5) Chinese Educational Institutions going global do not have sufficient information about the financial risks encountered in foreign country. Therefore, they do not know how to effectively avoid the traps and pitfalls which are deadly and may impact the growth and development of the Chinese Educational Institutions going global and may even lead to the collapse of Chinese Educational Institutions going global the sometimes in foreign countries. For instance, Tax risk is not only financial risk but also legal risk leading to financial loss and the reputation loss. Most of the Chinese Educational Institutions going global spend more time and efforts heading for the products, projects and market of the foreign country, but spend less time and efforts in conducting comprehensive research on land, environment protection, tax law and so on. The management of the Chinese Educational Institutions going global should clearly know that lack of knowledge tax laws in local countries may lead to the violation of the rules and may suffer severe punishment. Therefore, they are supposed to strengthen their vigilance of the management system to prevent potential risks. Tax risk prevention system, which is higher than financial system in standard, should be established in terms of organization structure, power distribution, and business procedure and information communication to avoid the tax risks.

6) At last but not least, Chinese Educational Institutions "going global" almost have no information of double taxation. Double taxation is another tax risk that Chinese Educational Institutions "going global" have to face up with. Hence, to avoid double taxation from home and abroad is another important issue for the management of the enterprise to consider. Many Chinese Educational Institutions "going global" conduct business and they know that they have to pay tax in foreign country and

\footnotetext{
2 Liu Yufang. Foreign Experience in Enterprise Going Global. Industry Research, 2009 12) : 15 to 16
}

region. Many people do not know that when the profit after tax is repatriated to China, it is included in the domestic taxable income and they also have to pay tax in China and do not know how to avoid double taxation by the two countries, the source country and the residence country. When domestic business and global business are closely related and domestic risks and global risks reconsidered simultaneously, balances can be achieved between domestic risks and global risks and things may become easier to handle. If the risks on one side are considered and the risks on the other side are ignored, risks may occur. In order to avoid double taxation risk, the management of the enterprise is supposed to fully understand the provisions of avoidance of double tax and tax evasions of the tax treaty signed by contracted parties. Till the end of 2013, China has signed 98 tax treaties with different countries and regions in the world.3 However, it is a pity that these tax treaties are mainly used by global enterprises but seldom by domestic enterprises. Chinese Educational Institutions "going global" should learn the detailed provisions of the tax treaties to protect their legal tax rights and interests and to avoid double taxation risk. And negotiation procedure can be launched to seek help from the domestic tax authority to handle tax issue. ${ }^{4}$

\section{B. Suggestions and Advices Raised for the Chinese Educational Institutions Going Global}

Therefore, according to the problems and challenges faced by the Chinese Educational Institutions going global mentioned in the part of 2.1, some suggestions and advices are raised for the Chinese Educational Institutions going global.

1) Chinese Educational Institutions are supposed to value different tradition and culture between China and foreign countries. They are supposed to conduct more research in local culture and tradition and to collect more background information about the foreign party. When they promote the image of the enterprise, they should do it by the way the local enterprises and individuals can accept easily instead of doing things in a domestic way. In other words, their practice is supposed to be in line with foreign practices.

2) Chinese Educational Institutions are supposed to fully exploit various resources to reduce the inconvenience caused by the difference existed in cultural and institutional difference between China and foreign countries to the greatest extent. In terms of the evaluation and approval of the new project, Chinese Educational Institutions should not only contact with intermediaries such as accounting agencies, tax agencies and law firms but also contact closely with the officials who are in charge of the examination and the approval of the project to let them have more information about the enterprise and avoid the traps in administrative procedures.

\footnotetext{
3 The Yearbook of Taxation, 2012,122-123

4 Yang Guozheng, Enterprise going global. Research of Education.2013 (8)
} 
3) Chinese Educational Institutions going global should keep good relationship with local enterprises and individuals. They are supposed to cooperate closely with the local enterprise and employee local talent as much as possible. Moreover, Chinese Educational Institutions should keep close relationship with the political representatives to let them know that the contribution of the Chinese Educational Institutions to the increase of the employment and the development of local economies. In addition, Chinese Educational Institutions should also contact closely with the media that is very powerful.

4) Chinese Educational Institutions Going Global should attach importance to the Institution publicity strategy. They should prepare for a nicely made brochure for local people to have sufficient information about the virtues of the enterprises, including advanced technology and the development prospect of the Chinese Educational Institutions and so on. The brochure of foreign language version is very important and people concerned should understand and have great interest to read. In terms of carrying out social liability, Chinese Educational Institutions should let the people know the great contribution of the enterprise to local economy development. This has been the best opportunity to promote the image of the enterprise. ${ }^{5}$

5) Chinese Educational Institutions going global should have sufficient information about the financial risks encountered in foreign country. They should know how to effectively avoid the traps and pitfalls which are deadly and may impact the growth and development of the Chinese Educational Institutions going global and may even lead to the collapse of Chinese Educational Institutions going global the sometimes in foreign countries. So that in order to make the Chinese Educational Institutions have a healthy, steady and sustainable growth on their way for going global, Chinese Educational Institutions going global should not only spend more time and efforts heading for the product, project, program and market of the foreign country; they should also spend more time and effort to conduct comprehensive research on land, environment protection, tax law and so on. Especially, Lack of knowledge tax laws in local countries may lead to the violation of the rules and may suffer severe punishment. Therefore, they are supposed to strengthen their vigilance of the management system to prevent potential risks. Tax risk prevention system, which is higher than financial system in standard, should be established in terms of organization structure, power distribution, and business procedure and information communication to avoid the tax risks.

6) Chinese Educational Institutions "going global" almost have no information about the problem of double taxation. Double taxation is another tax risk that Chinese Educational Institutions "going global" have to face up with Since Double taxation is a very complicated issue. It has to be carefully handled by the Chinese Educational Institutions "going global". Hence, to avoid double taxation from home and abroad is another important issue for the management of the enterprise to consider. Many Chinese Educational Institutions "going global" conduct business and pay tax mainly in foreign country and region. When the profit after tax is repatriated to China, it is included in the domestic taxable income. In fact, domestic business and global business are closely related and domestic risks and global risks can be considered simultaneously. If the risks on one side are considered and the risks on the other side are ignored, risks may occur. In order to avoid double taxation risk, the management of the enterprise is supposed to fully understand the provisions of avoidance of double tax and tax evasions of the tax treaty signed by contracted parties. Till the end of 2013, China has signed 98 tax treaties with different countries and regions in the world. However, it is a pity that these tax treaties are mainly used by global enterprises but seldom by domestic enterprises. Chinese Educational Institutions "going global" should learn the 5 detailed provisions of the tax treaties to protect their legal tax rights and interests and to avoid double taxation risk. And negotiation procedure can be launched to seek help from the domestic tax authority to handle tax issue.

\section{CONCLUSIONS AND IMPLICATIONS}

In order to avoid various risks and to ensure sustainable growth and development of Chinese Educational Institutions going global, there are several suggestions for them to follow:

\section{A. Chinese Educational Institutions Going Global are supposed to value different tradition and culture between China and foreign countries.}

B. Chinese Educational Institutions Going Global are supposed to fully exploit various resources to reduce the inconvenience caused by the difference existed in cultural and institutional difference between China and foreign countries to the greatest extent.

C. Chinese Educational Institutions Going Global should keep good relationship with local enterprises and individuals.

\section{Chinese Educational Institutions Going Global should} attach importance to the Institution publicity strategy.

E. Chinese Educational Institutions Going Global also encounter tax risk that is not only financial risk but also legal risk leading to financial loss and the reputation loss.

F. Double taxation is another tax risk that Chinese Educational Institutions "going global" have to face up with.

As long as the Chinese Educational Institutions "going global" can follow the advice raised above, they can detect potential risks at an early age and avoid risks and pitfalls to a certain extent.

\footnotetext{
5 Yang Guozheng, Case Study for Enterprise Going Global. Research of Education.2013 (8):21-26
} 


\section{ACKNOWLEDGEMENTS}

This research paper is under the International Cooperation Project of Henan Provincial Science and Technology Bureau: Study on Tax Loss of Sino-foreign Cooperated University; Number of the project: 134300510042.

\section{REFERENCES}

[1] Yang Xue. Analysis for Chinese Educational Institution Going Global, Research of Education.2011 (9)

[2] Liu Yufang. Foreign Experience in Enterprise Going Global. Industry Research, 2009 12) : 15 to 16

[3] The Yearbook of Taxation, 2012,122-123

[4] Yang Guozheng, Case Study for Enterprise Going Global. Research of Education.2013 (8):21-26 